Cyberbullying and adolescent well-being in England: a population-based cross sectional study

Andrew K. Przybylski, $\mathrm{PhD}^{1,2}$ and Lucy Bowes, $\mathrm{PhD}^{2}$

Affiliations: 1. Oxford Internet Institute, University of Oxford, United Kingdom. 2. Department of Experimental Psychology, University of Oxford, United Kingdom.

Address correspondence to: Andrew K. Przybylski, Oxford Internet Institute, 1 St. Giles' Oxford, Oxfordshire, OX1 3JS, United Kingdom, andy.przybylski@oii.ox.ac.uk, +44 (0) 1865287230 .

Short title: Cyberbullying prevalence

Abbreviations: None.

Key Words: bullying, cyberbullying, adolescents, mental well-being

Funding Source: LB is supported by a Leverhulme Early Career Research Fellowship. No funding was secured specifically for this study.

Financial Disclosure: The authors have no financial relationships relevant to this article to disclose.

Conflict of Interest: The authors have no conflicts of interest to disclose.

Clinical Trial Registration: Not applicable. 


\section{Cyberbullying and adolescent well-being in England: a population-based cross sectional study}

BACKGROUND: Bullying is a major public health problem. We aimed to estimate the prevalence of cyberbullying and traditional bullying among adolescents in England, and evaluate its relative impacts on mental well-being.

METHODS: We analysed data from a nationally representative cross sectional study of 120,115 English adolescents aged 15, who completed surveys between September 2014 and January 2015. Mental well-being was assessed using the Warwick-Edinburgh Mental Wellbeing Scale.

OUTCOMES: Of the 110,788 adolescents who completed measures of bullying, 33,363 (adjusted: $30.3 \%$ total, $36.4 \%$ females, $24.4 \%$ males) reported any form of significant bullying in the past couple of months. A total of 29,302 (26.6\% total, $31.1 \%$ females, $24.2 \%$ males) reported physical, verbal and relational (i.e. traditional) bullying only, whilst 406 ( $0.4 \%$ total, $0.5 \%$ females, $0.2 \%$ males $)$ reported only cyber-victimization, and $3,655(3.4 \%$ total, $4.8 \%$ females, $2.0 \%$ males) reported both traditional and cyberbullying. Both kinds of victimization were related to poorer mental well-being (adjusted analyses, traditional: $b=$ 1.99, $S E=0.01$; cyber: $b=-0.86, S E=0.06)$. Cyber-victimization accounted for less than $0.1 \%$ of observed variability in mental well-being compared to $5.0 \%$ of variability accounted for by traditional victimization.

INTERPRETATION: Traditional bullying is eight times more common among English adolescents than cyberbullying. Whilst both forms of bullying were associated with poorer mental well-being, cyberbullying accounted for a very small share of variance after adjustment for offline bullying and other covariates.

FUNDING: L.B. is supported by a Leverhulme Early Career Research Fellowship. No funding was secured specifically for this study. 


\section{Cyberbullying and adolescent well-being in England: a population-based cross sectional study}

Bullying is a major public health problem; adolescents who are victimised by their peers are at increased risk of multiple negative health outcomes. Population attributable fractions in the range of $25-40 \%$ suggest that a substantial proportion of mental health problems including depression and self-harm may be attributable to bullying if this is a causal relationship $(1,2)$. Given children's use of the Internet has doubled in the past decade (3), much research has focused on the phenomena of 'cyberbullying' - repeated, intentional aggression that takes place in an electronic context (e.g., e-mail, blogs, instant messages, text messages) and is targeted at a person who cannot easily defend him- or herself (4). Concerns have been raised that cyberbullying has the potential to cause more harm than traditional bullying due to the relative anonymity of perpetrators in many cases, larger audiences, increasing prevalence and permanence of posted messages (5). There remains much debate over whether cyberbullying may be more or less strongly associated with harmful outcomes than traditional bullying (4-9).

Prevalence rates of cyberbullying vary, in part due to the lack of a standardized definition, and validated cut-offs, as well as non-nationally representative samples. A study by Vazsonyi and colleagues (10) published in 2012 sampled 1,032 UK students as part of a larger study of 9-16 year olds from 25 European countries (EU Kids Online II Project) and found that $8 \%$ self-reported having been cyber bullied compared to $21 \%$ reporting any form of traditional bullying. In a more recent study of 2,745 11-16 year olds in five secondary schools in the Midlands, UK, 29\% reported having been bullied in the past six months, but only $1 \%$ of adolescents reported only cyberbullying and no traditional bullying (11). Some studies have reported gender differences in prevalence rates, with girls reporting more cyberbullying victimization (4). This is in keeping with studies of traditional bullying involvement $(9,11,12)$. Typically, boys have been found to be at increased risk of 
involvement in direct forms of bullying both as victims and perpetrators, whilst girls are more likely to both experience and engage in indirect forms of bullying (13). Given the rise in use of mobile and online technologies among young people, an up to date estimation of the current prevalence of cyberbullying in the UK is needed. We report data from the largest study to date estimating the prevalence of bullying and cyberbullying among a nationally representative sample of 120,115 adolescents aged 15 years across the England, and estimate its impact on an important and widely studied aspect of child and adolescent health, mental well-being.

Mental well-being is more than the absence of psychopathology or ill-health (14), and reflects life satisfaction, fulfilling social relationships, purpose in life, and a subjective sense of flourishing (15). Mental well-being may be protective for a range health outcomes, as well as higher educational attainment in childhood and adolescence, and better occupational functioning in adulthood (16). The promotion of mental well-being has large-scale social and economic benefits, placing this as an important component of public health policy (17). This is of particular relevance to the UK, which was recently ranked 20th of $27 \mathrm{EU}$ countries on the mental well-being index (18). The impact of bullying on adolescents' mental well-being has been largely overlooked, with research focusing primarily on bullying as a risk factor for psychiatric morbidity $(1,19,20)$. It is not known whether cyberbullying is related to mental well-being independent of involvement in traditional bullying. The promotion of well-being is now one of the key UN Sustainable Development Goals, and an analysis of the relationship between bullying and adolescent well-being is timely.

The aims of the present research are threefold. First, we report an up to date estimate of the prevalence of both traditional and cyberbullying among a large-scale, nationally representative sample of English 15 year olds. Second, we estimate the magnitude of the relations between these forms of bullying and mental well-being. Finally, we estimate the 
extent to which cyberbullying, a new medium for bullying behaviours, is related to mental well-being once the impact of more traditional forms of bullying has been accounted for.

\section{Method}

\section{Participants}

Data were collected as part of the What about Youth Study conducted by the Health and Social Care Information Centre (now NHS Digital) between 22nd September 2014 and 9th January 2015. Participants were identified using the United Kingdom's Department for Education National Pupil Database. Fieldwork covered a total of 150 local authorities across England with the aim of making sufficient observations to attain a $+/-0.3 \%$ margin of error at a 95\% confidence interval for English youths aged 15 years across the country. A prenotification letter was sent to parents or carers of participants giving them the opportunity to opt their child out of the survey. As indicated in Figure 1, a total of 120,115 participants responded with usable data through the use of paper $(n=100,850)$ or online questionnaires $(n$ $=19,265)$ and sensitivity analyses comparing the direction, magnitude, and significance of the results for each mode indicated the pattern of findings did not vary between these methods. Response rates were typical of large scale surveys of this kind, and varied by gender, with adjusted response rates of 35 per cent for boys and 49 per cent for girls (21). Response rates also varied across LAs, with the lowest adjusted rates recorded in the London Boroughs of Kensington and Chelsea and Hammersmith and Fulham (both 27.8\%). The highest response rates were recorded in Devon (49.6\%), Wiltshire (49.7\%), Poole (49.7\%) and Somerset (50.1\%). In order to correct for differences in the levels of non-response by different groups of the population, a non-response weight was used based on key variables for which it was possible to compare the whole population and the achieved sample. These were ethnicity, free school meals eligibility and indices of multiple deprivation (IMD) 
quintile. Further details of the weighting procedure used can be found in the What About Youth Technical Report (22).

\section{Ethics and Open Science Practices}

Ethical review was conducted by the United Kingdom's National Children's Bureau and review for data analysis was conducted by the research ethics committee at University of Oxford (C1A16015). All data, materials, and code are available for download using the Open Science Framework (osf.io/6xkdv/).

\section{Outcome variable - Mental well-being}

The Warwick-Edinburgh Mental Well-being Scale, a unidimensional 14-item selfreport instrument validated for use in general population samples of those aged 13 years and above, was used to measure psychosocial health, well-being, and functioning. Participants used a five point scale that ranged from 0 "None of the time" to 5 "All of the time". A total of 117,842 participants $(98.1 \%)$ completed this measure which showed robust internal consistency $(\alpha=.90)$ and individual scores were computed for each participant by summing items $(M=47.63, S D=9.45)$.

\section{Explanatory variable - Traditional and Cyberbullying.}

Participants completed a brief 8-item checklist derived from the revised Olweus Bully/Victim Questionnaire (23) meant to assess the extent to which they had recently experienced other children directing different types of bullying towards themselves. Bullying was described as “...when another person, or a group of people, say or do nasty and unpleasant things to him or her. It is also bullying when a person is teased repeatedly in a way he or she does not like or when he or she is deliberately left out of things. Bullying may happen over the Internet or by text or phone messages. It is not bullying when a person is teased in a friendly and playful way." Six statements reflecting traditional bullying (physical, verbal and relational), e.g. "I was hit, kicked, pushed, shoved around, or locked indoors", 
"Other people left me out of things on purpose, excluded me from their group of friends, or completely ignored me" and two reflected cyberbullying, e.g. "Someone sent mean instant messages, wall postings, emails and text messages, or created a website that made fun of me." were rated by participants using a 5-point response scale that ranged from $0=$ "I haven't been bullied this way in the past couple of months" $1=$ "It has happened once or twice," 2 = "2 or 3 times a month," 3 = "Two or three times a month," to $4=$ "Several times a week." A total of 110,788 adolescents (92.2\%) completed the assessment and Table 1 presents the reported frequencies of each form of bullying. A cut-off " 2 or 3 times a month" was selected to represent significant bullying in line with existing research (23) to distinguish between young people who were meaningfully involved in bullying and those who were not. Using this well-validated cut-off, $30.0 \%$ of participants (adjusted) reported significant traditional bullying and 3.8\% participants reported significant cyberbullying. In order to obtain a measure of the degree of exposure to bullying, we summed the number of items of traditional bullying and, separately, cyberbullying each participant endorsed at greater than "2 or 3 times a month".

\section{Control Variables}

Participant gender, material deprivation, and being a member of an ethnic minority were treated as control variables on the basis of previous research suggesting that these factors may be associated with differences in prevalence of bullying or its correlates (24-26). Participants who self-identified as male were coded 1 (females coded 0 ). In line with the approach taken by the United Kingdom Department of National Statistics postcode data was used to determine material deprivation; if participants lived in a relatively deprived local authority district, lower two quintiles of the multiple deprivation index they were coded 1 (if not they were coded 0 ). If participants identified as having an ethnic background other than White they were coded 1 (if not they were coded 0 ). 


\section{Statistical Analyses}

In line with the primary aims of the present research three kinds of statistical analyses were performed. First, descriptive statistics estimating the period prevalence of both forms traditional and cyberbullying were computed. Second, non-parametric (i.e. Kendall's Tau-b) correlation analyses estimating the strength, direction, and significance of the relations between reporting significant recent experience with either form of bullying and psychological well-being were conducted. Finally, multiple regression models were used to estimate the strength, direction, and significance of the relations linking traditional and cyberbullying to psychological well-being holding variability in the control variables constant. In this model we used the degree of exposure to each form of bullying, the sum of the items participant endorsed at greater than " 2 or 3 times a month". These primary analyses were supplemented with three sensitivity tests. The first two examined life satisfaction as an alternative outcome using both correlational and multiple regression models following the procedure used for psychological well-being. The third sensitivity test was a multinomial regression model which examined the relative odds that exposure to each form of bullying or a combination of the two related to the chance of adolescents reported scores that fell in the bottom $20 \%$ of the psychological well-being distribution.

\section{Results}

\section{Bullying Prevalence}

Nearly one third (30.3\%) of the 110,788 adolescents completing the bullying measures in our sample reported experiencing some form of bullying at least two or three times in the past two months, 29,302 (26.6\%) reported only traditional bullying, $406(0.4 \%)$ reported only cyberbullying, and 3,655 (3.4\%) reported both traditional and cyberbullying. Table 1 presents the prevalence of individual forms of bullying at a $+/-0.3$ percentage point margin of error at the $95 \%$ confidence interval for this population of adolescents and shows 
that adolescent girls reported significantly higher levels of all forms of victimisation, excepting physical bullying. This pattern replicates earlier research suggesting a gender imbalance in prevalence rates of bullying (27). The most common forms of bullying were relational, including having lies or false rumours spread about a person, and being called mean names, being made fun of, or teased in a hurtful way. As with other studies our data indicated $90.0 \%$ of those who experienced cyberbullying also reported significant traditional bullying.

\section{Bullying and Mental Well-Being}

Examination of the average mental well-being score among adolescents in our survey presented in Figure 2 indicated well-being monotonically declined as a function of combination of bullying experienced. Those reporting no bullying reporting the highest levels of well-being and those reporting both forms of bullying the lowest. Results from zero-order correlation analyses (Kendall's Tau-b) indicate that those reporting any significant traditional $\left(r_{T}=-.21, p<.001\right)$ and cyberbullying $\left(r_{T}=-.11, p<.001\right)$ experienced lower well-being.

To test the extent to which traditional and cyberbullying independently predicted well-being a multi-step multiple regression models was evaluated. In this model we regressed the outcome measure, mental well-being onto the control variables in the first step, and the explanatory variable in the second step. Results from regression models adjusting for control factors (Table 2) and post stratification weighting indicate that although both forms of bullying related to well-being, cyberbullying accounted for less than $0.1 \%$ of observed variability in well-being compared to $5.0 \%$ of variability accounted for by traditional bullying.

\section{Sensitivity Analyses}

To examine whether associations with well-being were practically meaningful, we performed a multinomial logistic regression to compare how different experiences of bullying 
predicted being in the bottom $20 \%$ of the total well-being distribution (Table 3 ) holding constant variability linked to the control variables. Those who reported no regular bullying of either type (i.e. less than 2-3 times per month) were used as the reference category, and those who reported the presence of bullying (at least 2-3 times per month) in terms of traditional only, online only, and both were used as dummy-coded predictors. Results from this analysis indicated that, compared to those reporting no recent bullying, those who reported regularly experiencing online bullying only were more likely to be in the bottom $20 \%$ of scores for mental well-being (Odds Ratio $=1.83 ; 95 \% \mathrm{CI}: 1.64$ to 2.05$)$, as were those who reported regularly experiencing traditional bullying (Odds Ratio $=2.62 ; 95 \%$ CI: 2.58 to 2.66 ), and this pattern was most pronounced for those who reported regularly experiencing both forms of bullying (Odds Ratio $=5.14 ; 95 \%$ CI: 4.98 to 5.31$)$.

A further supplementary analysis considering a general measure of adolescent life satisfaction was also examined. Correlations between this four-item scale ( $\alpha=.77, M=7.07$, $S D=1.91)$ indicated life satisfaction was negatively correlated with both traditional $\left(r_{T}=\right.$ $.26, p<.001)$ and cyberbullying $\left(r_{T}=-.13, p<.001\right)$. Results a regression analysis holding the observed variability in the control variables constant, mirror those found for mental wellbeing. Traditional bullying accounted for $7.8 \%$ of observed variability in life satisfaction and cyberbullying less than $0.1 \%$ (Table 4 ).

\section{Discussion}

This is the largest study to date to examine prevalence of traditional and cyberbullying in British adolescents. Nearly one third of English adolescents studied reported experiencing significant bullying in the past couple of months. With the exception of physical bullying, girls reported significantly higher levels of all forms of aggressive behaviour studied. In this large-scale study, we found gender differences in self-reported prevalence rates, supporting previous studies that suggested girls may be more involved in indirect forms 
of bullying than boys (13). It remains possible that gender norms regarding bullying may play a role in self-reporting. Cyberbullying was less common than traditional forms, with one-intwenty girls and boys reporting recent significant experience in the last couple of months. Prevalence rates for both types of bullying reported in this study varied from than those reported in 2012 by Vazsonyi and colleagues (10), however given differences in measurement scales used, we cannot comment on whether this indicates a change in rates of bullying. Cyberbullying most commonly occurred alongside traditional bullying; only $0.4 \%$ of participants reported that they experienced cyberbullying alone as many forms of relational bullying, such as spreading rumours happen in online and offline contexts. We found that both traditional and cyberbullying were independently associated with lower mental well-being, however only the relationship between traditional bullying and well-being was robust and explained a meaningful share of variance in this large sample. These findings lend support to the position by Wolke and colleagues (11) that cyberbullying is unlikely to provide a source for new victims but can best be understood as a new avenue for victimisation for those already suffering traditional forms of bullying (28). Of concern, adolescents who reported having experienced traditional and cyberbullying in the last couple of months were most likely to have low mental well-being scores (i.e. scores falling in the lowest $20 \%$ of the distribution).

A limitation of our study is that both our measures of bullying and mental well-being were self-reported. Adolescents with lower levels of mental well-being may also be more likely to perceive or report incidences of victimisation. This may inflate both prevalence rates of bullying and the relationship with mental well-being. Although we adopted a wellvalidated measure and cut-off informed by the work of Olweus and colleagues (23), there is no 'gold standard' measure of bullying, with studies reporting that self-report measures appear to be equally valid compared to parental or teacher methods (29). Peer nomination 
methods, though providing high reliability and validity, would not be feasible on a survey as large as ours but future large-scale survey work could build on these findings by using a direct measure of material deprivation (in place of postcode data) and ask about bullying with respect to a longer time frame than a couple of months in line with widely used six month window $(23,28,29)$. A second limitation is that the What About Youth Study did not include any measures of mental health problems, nor did it assess exposure to abuse or neglect, and thus we were unable to adjust for the potential confounding effect of these variables. A third limitation of our study is that it was cross sectional. Whilst this is suitable for estimating prevalence, we are unable to estimate direction of effects when examining the relationship between bullying and mental well-being. It remains possible that adolescents with low mental well-being are more at risk of being bullied by their peers. Findings from other studies suggest that this relationship might be reciprocal, leading to a negative cycle of bullying and low mental well-being (30). Finally, because of the format of our study only a limited number of control variables could be included and only $92.2 \%$ of participants completed the bullying measures and analyses indicated that non-white participants were slightly less likely to complete the measure $\left(r_{T}=-0.08\right)$. With this in mind, a large-scale experience sampling design that tracks a diverse sample of young people over time is needed to determine the extent to which cyberbullying is independently related to mental well-being over time over and above any links with traditional forms of bullying. Importantly, such a study should examine how personal and background factors might serve to moderate negative youth outcomes.

\section{Conclusions}

In our sample, just under one-in-five of English adolescents aged 15 years reported on their recent experience of bullying. Our findings suggests that nearly one third of these adolescents have experienced regular bullying in the past couple of months but only one in twenty-five 
reporting significant cyberbullying. Given that cyberbullying rarely occurred or had

observable effects on well-being in isolation, the present results suggest interventions meant to curb the possible negative consequences of cyberbullying will be effective insofar as they consider and are sensitive to the dynamics of traditional forms of bulling. Our findings support the urgent need for evidence-based interventions that holistically target both forms bullying in adolescence (31) and are in stark contrast to media reports and the popular perceptions that young people are now more likely to be victims of cyberbullying than traditional forms (32). That understood, as Internet connectivity become an increasing intrinsic part of modern childhood initiatives fostering resilience in online and every day contexts will be needed.

\section{Research in Context}

\section{Evidence before this study}

We searched PsycINFO and Medline to identify potential literature published before May $19^{\text {th }} 2017$, using the search string "(bulli* OR bully* OR peer victimization) and (cyber*) and (prevalence)". We identified 257 peer reviewed articles in PsycINFO and 132 in Medline, of which 95 provided relevant data on prevalence. Prevalence rates for cyberbullying were generally reported to be lower than for traditional bullying, though it has been suggested that cyberbullying may be on the rise. Few studies used nationally representative samples.

Systematic reviews support an association between adolescent bullying and poor mental wellbeing outcomes. Some claim that cyberbullying may place adolescents at greater risk of poor mental well-being than traditional bullying, however evidence is conflicting.

\section{Added value of this study}

Our nationally-representative sample of 120,115 English adolescents is the largest study to date that examines the prevalence rates of traditional and cyberbullying in the. We found that prevalence rates of cyberbullying (3.7\%) are lower than that of offline bullying $(29.7 \%)$. Cyberbullying was independently associated with poor well-being over and above effects of traditional bullying, though explained less variance.

\section{Implications of all the available evidence}

Our results and previous literature support an association between bullying (cyber- and traditional) and poorer well-being. The findings support the need for evidence-based interventions that target both traditional bullying and cyberbullying. Social media and internet connectivity are becoming an increasingly intrinsic part of modern childhood, and initiatives fostering resilience in online and every day contexts are needed. 


\section{Authors contributions}

Dr. Andrew K. Przybylski (PhD, University of Oxford) conceptualized the project with Dr. Bowes (PhD, University of Oxford). Drs. Przybylski and Bowes conducted data analyses, both authors have had full access to the data, and take responsibility for its integrity and the accuracy of the data analysis. This paper is the first and only reporting of these data. Both authors made substantial contributions to manuscript write-up.

\section{Declaration of Interests}

Dr. Bowes is supported by a Leverhulme Early Career Research Fellowship. The Leverhulme Trust had no role in the writing of the manuscript or the decision to submit it for publication. No funding was secured specifically for this study. The authors declared no conflicts of interest. 


\section{References}

1. Bowes L, Joinson C, Wolke D, Lewis G. Peer victimisation during adolescence and its impact on depression in early adulthood: prospective cohort study in the United Kingdom. BMJ. 2015 Jun 2;350:h2469.

2. Fisher HL, Moffitt TE, Houts RM, Belsky DW, Arseneault L, Caspi A. Bullying victimisation and risk of self harm in early adolescence: longitudinal cohort study. BMJ. 2012 Apr 26;344:e2683.

3. Ofcom. Children and parents: Media use and attitudes report 2015 [Internet]. 2015 [cited 2016 May 25]. Available from: http://stakeholders.ofcom.org.uk/market-dataresearch/other/research-publications/childrens/children-parents-nov-15/

4. Slonje R, Smith PK. Cyberbullying: another main type of bullying? Scand J Psychol. 2008 Apr;49(2):147-54.

5. Sticca F, Perren S. Is cyberbullying worse than traditional bullying? Examining the differential roles of medium, publicity, and anonymity for the perceived severity of bullying. J Youth Adolesc. 2013 May;42(5):739-50.

6. Landstedt E, Persson S. Bullying, cyberbullying, and mental health in young people. Scand J Public Health. 2014 Jun;42(4):393-9.

7. Messias E, Kindrick K, Castro J. School bullying, cyberbullying, or both: correlates of teen suicidality in the 2011 CDC Youth Risk Behavior Survey. Compr Psychiatry. 2014 Jul;55(5):1063-8.

8. Sampasa-Kanyinga H, Roumeliotis $\mathrm{P}, \mathrm{Xu} \mathrm{H}$. Associations between Cyberbullying and School Bullying Victimization and Suicidal Ideation, Plans and Attempts among Canadian Schoolchildren. PLOS ONE. 2014 Jul 30;9(7):e102145.

9. Waasdorp TE, Bradshaw CP. The Overlap Between Cyberbullying and Traditional Bullying. J Adolesc Health. 2015 May 1;56(5):483-8.

10. Vazsonyi AT, Machackova H, Sevcikova A, Smahel D, Cerna A. Cyberbullying in context: Direct and indirect effects by low self-control across 25 European countries. Eur J Dev Psychol. 2012 Mar 1;9(2):210-27.

11. Wolke D, Lee K, Guy A. Cyberbullying: a storm in a teacup? Eur Child Adolesc Psychiatry [Internet]. 2017 Feb 10 [cited 2017 Apr 24]; Available from: http://link.springer.com/10.1007/s00787-017-0954-6

12. Modecki KL, Minchin J, Harbaugh AG, Guerra NG, Runions KC. Bullying prevalence across contexts: a meta-analysis measuring cyber and traditional bullying. J Adolesc Health Off Publ Soc Adolesc Med. 2014 Nov;55(5):602-11.

13. Rivers I, Smith PK. Types of bullying behaviour and their correlates. Aggress Behav. 1994;20(5):359-68.

14. Patalay P, Fitzsimons E. Correlates of Mental Illness and Wellbeing in Children: Are They the Same? Results from the UK Millennium Cohort Study. J Am Acad Child 
Adolesc Psychiatry [Internet]. 2016 Jun 28 [cited 2016 Aug 4];0(0). Available from: /article/S0890-8567(16)30284-2/abstract

15. Parkinson J. Establishing a core set of national, sustainable mental health indicators for adults in Scotland: Final report [Internet]. 2007. Available from: http://www.healthscotland.com/uploads/documents/5798Adult $\% 20$ mental\%20health\%20indicators\%20-\%20final\%20report.pdf

16. Stewart-Brown S. Promoting health in children and young people: identifying priorities. J R Soc Promot Health. 2005 Mar 1;125(2):61-2.

17. Stranges S, Samaraweera PC, Taggart F, Kandala N-B, Stewart-Brown S. Major healthrelated behaviours and mental well-being in the general population: the Health Survey for England. BMJ Open. 2014 Sep 1;4(9):e005878.

18. The Organisation for Economic Co-operation and Development. OECD Your Better Life Index [Internet]. 2016. Available from: http://stats.oecd.org/index.aspx?DataSetCode=BLI

19. Copeland WE, Wolke D, Angold A, Costello E. ADult psychiatric outcomes of bullying and being bullied by peers in childhood and adolescence. JAMA Psychiatry. 2013 Apr $1 ; 70(4): 419-26$.

20. Lereya ST, Copeland WE, Costello EJ, Wolke D. Adult mental health consequences of peer bullying and maltreatment in childhood: two cohorts in two countries. Lancet Psychiatry. 2015 Jun;2(6):524-31.

21. Galea S, Tracy M. Participation rates in epidemiologic studies. Ann Epidemiol. 2007 Sep;17(9):643-53.

22. Ipsos MORI. What About YOUth? Survey, 2014. UK Data Service; 2016.

23. Solberg ME, Olweus D. Prevalence estimation of school bullying with the Olweus Bully/Victim Questionnaire. Aggress Behav. 2003 Jun;29(3):239-68.

24. Cook CR, Williams KR, Guerra NG, Kim TE, Sadek S. Predictors of bullying and victimization in childhood and adolescence: A meta-analytic investigation. Sch Psychol Q. 2010;25(2):65-83.

25. Due P, Merlo J, Harel-Fisch Y, Damsgaard MT, soc M scient, Holstein BE, et al. Socioeconomic Inequality in Exposure to Bullying During Adolescence: A Comparative, Cross-Sectional, Multilevel Study in 35 Countries. Am J Public Health. 2009 May;99(5):907-14.

26. Tippett N, Wolke D, Platt L. Ethnicity and bullying involvement in a national UK youth sample. J Adolesc. 2013 Aug;36(4):639-49.

27. Nansel TR, Overpeck M, Pilla RS, Ruan WJ, Simons-Morton B, Scheidt P. Bullying Behaviors Among US Youth: Prevalence and Association With Psychosocial Adjustment. JAMA J Am Med Assoc. 2001 Apr 25;285(16):2094-100. 
28. Olweus D. Cyberbullying: An overrated phenomenon? Eur J Dev Psychol. 2012 Sep;9(5):520-38.

29. Shakoor S, Jaffee SR, Andreou P, Bowes L, Ambler AP, Caspi A, et al. Mothers and children as informants of bullying victimization: results from an epidemiological cohort of children. J Abnorm Child Psychol. 2011 Apr;39(3):379-87.

30. Reijntjes A, Kamphuis JH, Prinzie P, Telch MJ. Peer victimization and internalizing problems in children: A meta-analysis of longitudinal studies. Child Abuse Negl. 2010 Apr;34(4):244-52.

31. Della Cioppa V, O’Neil A, Craig W. Learning from traditional bullying interventions: A review of research on cyberbullying and best practice. Aggress Violent Behav. 2015 Jul;23:61-8.

32. Mascellino A. Children are "more likely to be bullied online than in the playground" [Internet]. mirror. 2017 [cited 2017 May 19]. Available from:

http://www.mirror.co.uk/tech/your-children-safe-online-parents-9720544 
Table 1. Observed Prevalence of Different Forms of Traditional Bullying and Cyberbullying for Female and Male Adolescents.

\begin{tabular}{|c|c|c|c|c|c|c|c|}
\hline \multirow{2}{*}{$\begin{array}{l}\text { Type } \\
\text { Traditional bullying }\end{array}$} & \multirow[t]{2}{*}{ Frequency } & \multicolumn{2}{|c|}{ Total } & \multicolumn{2}{|c|}{ Females } & \multicolumn{2}{|c|}{ Males } \\
\hline & & & & & & & \\
\hline I was called mean names, was & Not bullied this way & $67 \cdot 0$ & $(74,866)$ & $64 \cdot 5$ & $(3,7880)$ & $69 \cdot 5$ & $(36,986)$ \\
\hline made fun of, or teased in a & $1-2$ times & $21 \cdot 1$ & $(23,182)$ & $22 \cdot 7$ & $(12,969)$ & $19 \cdot 6$ & $(10,213)$ \\
\hline \multirow[t]{3}{*}{ hurtful way. $\%$} & 2-3 times a month & $4 \cdot 8$ & $(5,110)$ & $5 \cdot 5$ & $(3,020)$ & $4 \cdot 1$ & $(2,090)$ \\
\hline & 2-3 times a week & $3 \cdot 8$ & $(4,159)$ & $4 \cdot 1$ & $(2,296)$ & $3 \cdot 6$ & $(1,863)$ \\
\hline & Several times a week & $3 \cdot 3$ & $(3,471)$ & $3 \cdot 2$ & $(1,773)$ & $3 \cdot 3$ & $(1,698)$ \\
\hline Other people left me out of & Not bullied this way & $72 \cdot 0$ & $(79,882)$ & $64 \cdot 6$ & $(37,934)$ & $79 \cdot 2$ & $(41,948)$ \\
\hline things on purpose, excluded & $1-2$ times & $18 \cdot 6$ & $(20,676)$ & $23 \cdot 0$ & $(13,107)$ & $14 \cdot 3$ & $(7,569)$ \\
\hline me from their group of friends, & 2-3 times a month & $4 \cdot 4$ & $(4,778)$ & $5 \cdot 7$ & $(3,231)$ & $3 \cdot 0$ & $(1,547)$ \\
\hline \multirow[t]{2}{*}{ or completely ignored me. $\%$} & 2-3 times a week & $2 \cdot 7$ & $(2,905)$ & $3 \cdot 5$ & $(1,953)$ & $1 \cdot 9$ & $(952)$ \\
\hline & Several times a week & $2 \cdot 4$ & $(2,547)$ & $3 \cdot 2$ & $(1,713)$ & $1 \cdot 7$ & $(834)$ \\
\hline I was hit, kicked, pushed, & Not bullied this way & $91 \cdot 0$ & $(101,358)$ & $92 \cdot 9$ & $(54,019)$ & $89 \cdot 2$ & $(47,339)$ \\
\hline shoved around, or locked & $1-2$ times & $6 \cdot 3$ & $(6,758)$ & $5 \cdot 1$ & $(2,865)$ & $7 \cdot 5$ & $(3,893)$ \\
\hline \multirow[t]{3}{*}{ indoors. \% } & 2-3 times a month & $1 \cdot 2$ & $(1,262)$ & $1 \cdot 0$ & $(521)$ & $1 \cdot 5$ & $(741)$ \\
\hline & 2-3 times a week & $0 \cdot 8$ & $(815)$ & 0.6 & $(308)$ & $1 \cdot 0$ & $(507)$ \\
\hline & Several times a week & $0 \cdot 6$ & $(595)$ & $0 \cdot 4$ & $(225)$ & $0 \cdot 8$ & $(370)$ \\
\hline Other people told lies or & Not bullied this way & $70 \cdot 4$ & $(78,291)$ & $64 \cdot 3$ & $(37,720)$ & $76 \cdot 4$ & $(40,571)$ \\
\hline spread false rumours about & $1-2$ times & $20 \cdot 0$ & $(22,192)$ & $23 \cdot 6$ & $(13,542)$ & $16 \cdot 5$ & $(8,650)$ \\
\hline me and tried to make others & 2-3 times a month & $4 \cdot 9$ & $(5,356)$ & $6 \cdot 1$ & $(3,465)$ & $3 \cdot 7$ & $(1,891)$ \\
\hline \multirow[t]{2}{*}{ dislike me. $\%$} & 2-3 times a week & $2 \cdot 3$ & $(2,424)$ & $2 \cdot 8$ & $(1,547)$ & $1 \cdot 7$ & $(877)$ \\
\hline & Several times a week & $2 \cdot 4$ & $(2,525)$ & $3 \cdot 1$ & $(1,664)$ & $1 \cdot 7$ & $(861)$ \\
\hline Other people made fun of me & Not bullied this way & $83 \cdot 0$ & $(92,182)$ & $79 \cdot 4$ & $(46,311)$ & $86 \cdot 6$ & $(45,871)$ \\
\hline because of my body & $1-2$ times & $10 \cdot 8$ & $(11,899)$ & $13 \cdot 0$ & $(7,406)$ & $8 \cdot 6$ & $(4,493)$ \\
\hline \multirow[t]{3}{*}{ weight. \% } & 2-3 times a month & $2 \cdot 7$ & $(3,014)$ & $3 \cdot 5$ & $(1,981)$ & $2 \cdot 0$ & $(1,033)$ \\
\hline & $2-3$ times a week & $1 \cdot 7$ & $(1,861)$ & $2 \cdot 0$ & $(1,143)$ & $1 \cdot 4$ & $(718)$ \\
\hline & Several times a week & $1 \cdot 7$ & $(1,832)$ & $2 \cdot 1$ & $(1,097)$ & $1 \cdot 4$ & $(735)$ \\
\hline Other people made sexual & Not bullied this way & $80 \cdot 3$ & $(89,081)$ & $89 \cdot 6$ & $(44,119)$ & $94 \cdot 1$ & $(44,962)$ \\
\hline jokes, comments, or gestures & $1-2$ times & $11 \cdot 7$ & $(13,027)$ & $7 \cdot 5$ & $(8,199)$ & $4 \cdot 6$ & $(4,828)$ \\
\hline \multirow[t]{3}{*}{ to me. $\%$} & 2-3 times a month & $3 \cdot 3$ & $(3,638)$ & $1 \cdot 5$ & $(2,447)$ & $0 \cdot 7$ & $(1,191)$ \\
\hline & 2-3 times a week & $2 \cdot 5$ & $(2,707)$ & $0 \cdot 8$ & $(1,803)$ & $0 \cdot 2$ & $(904)$ \\
\hline & Several times a week & $2 \cdot 2$ & $(2,335)$ & $0 \cdot 7$ & $(1,370)$ & $0 \cdot 3$ & $(965)$ \\
\hline \multicolumn{8}{|l|}{ Cyberbullying } \\
\hline Someone sent mean instant & Not bullied this way & 91.9 & $(101,905)$ & $89 \cdot 6$ & $(52,080)$ & $94 \cdot 1$ & $(49,825)$ \\
\hline messages, wall postings, emails & $1-2$ times & $6 \cdot 0$ & $(6,658)$ & $7 \cdot 5$ & $(4,267)$ & $4 \cdot 6$ & $(2,391)$ \\
\hline and text messages, or created a & 2-3 times a month & $1 \cdot 1$ & $(1,177)$ & $1 \cdot 5$ & $(818)$ & $0 \cdot 7$ & $(359)$ \\
\hline \multirow[t]{2}{*}{ website that made fun of me. $\%$} & 2-3 times a week & $0 \cdot 5$ & $(520)$ & $0 \cdot 8$ & $(400)$ & $0 \cdot 2$ & $(120)$ \\
\hline & Several times a week & $0 \cdot 5$ & $(528)$ & $0 \cdot 7$ & $(373)$ & $0 \cdot 3$ & $(155$ \\
\hline Someone took unflattering or & Not bullied this way & $90 \cdot 9$ & $(100,598)$ & $88 \cdot 1$ & $(51,103)$ & $93 \cdot 7$ & $(49,495)$ \\
\hline inappropriate pictures of me & $1-2$ times & $6 \cdot 9$ & $(7,786)$ & $8 \cdot 9$ & $(5,121)$ & $5 \cdot 0$ & $(2,665)$ \\
\hline without permission and posted & 2-3 times a month & $1 \cdot 2$ & $(1,343)$ & $1 \cdot 7$ & $(991)$ & $0 \cdot 7$ & $(352)$ \\
\hline \multirow[t]{2}{*}{ them online. $\%$} & 2-3 times a week & $0 \cdot 5$ & $(551)$ & $0 \cdot 7$ & $(376)$ & $0 \cdot 3$ & $(175)$ \\
\hline & Several times a week & $0 \cdot 5$ & $(510)$ & 0.6 & $(347)$ & $0 \cdot 3$ & $(163)$ \\
\hline
\end{tabular}

Notes. The percentages reflect values from valid response data adjusted and weighted by representativeness of participants across England. Actual numbers, in parentheses, reflect raw observed counts out of a total of $n=110,788$ participants, of which $n=57,938$ were females, $n=52,850$ were males. 
Table 2. Linear Regression Model Examining the Effects of Bullying on Mental Well-Being.

\section{Std. $\quad 95 \% \mathrm{CI}$}

$b \quad$ Error $\quad \beta \quad p$

\section{Controls}

$\begin{array}{lrrrrrrr}\text { Male } & 5.04 & 0.27 & 4.98 & \text { to } & 5.09 & 0.27 & <\cdot 0001 \\ \text { Ethnic Minority } & 0.63 & 0.03 & 0.56 & \text { to } & 0.69 & 0.03 & <.0001 \\ \text { Material Deprivation } & -0.80 & -0.04 & -0.85 & \text { to } & -0.75 & -0.04 & <.0001\end{array}$

\section{Predictors}

$\begin{array}{llllllll}\text { Traditional Bullying } & -1.99 & 0.01 & -2.02 & \text { to } & -1.97 & -0.25 & <.0001\end{array}$

Cyberbullying

$\begin{array}{lllllll}-0.86 & 0.06 & -0.97 & \text { to } & -0.75 & -0.02 & <.0001\end{array}$

Notes. Coefficients reflect values adjusted and weighted by representativeness of participants across the England. B, unstandardized regression slope coefficients, CI, Confidence Interval, $\beta$, standardized regression slope coefficients. Note bullying behaviours reflect the number of traditional or cyberbullying experiences participants reported experiencing at least 2-3 times per month. 


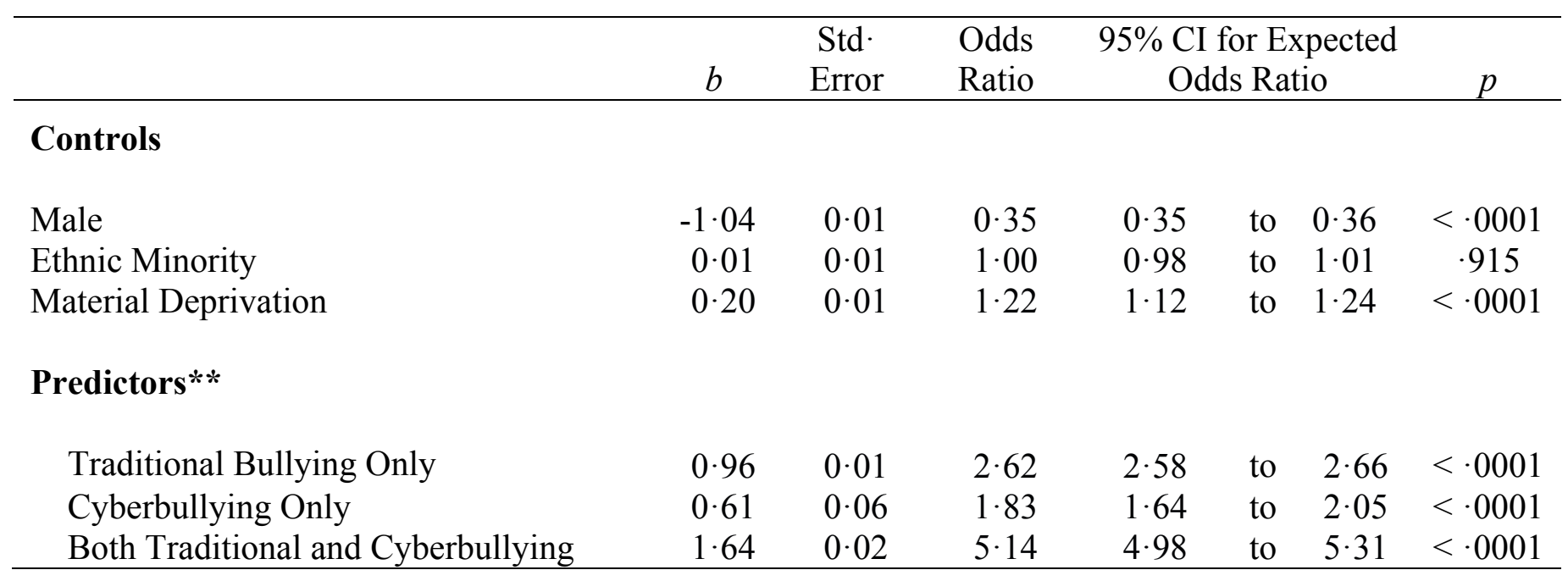

Notes. Coefficients reflect values adjusted and weighted by representativeness of participants across England. B, unstandardized regression slope coefficients; CI, Confidence Interval for the odds ratio $\beta$, standardized regression slope coefficients. ${ }^{*}$ The reference category is those in the upper 4 quintiles of Mental Well-being. **The reference category are those who reported neither form of bullying. Note bullying behaviours reflect reports of traditional or cyberbullying experiencing at least 2-3 times per month. 
Table 4. Linear Regression Model Examining the Effects of Bullying on Life Satisfaction.

\begin{tabular}{lllll}
\hline & Std & $95 \%$ CI & & \\
$b$ & Error & & $\beta$ & $p$ \\
\hline
\end{tabular}

\section{Controls}

$\begin{array}{lrrrrrrr}\text { Male } & 0.94 & 0.01 & 0.93 & \text { to } & 0.95 & 0.25 & <.0001 \\ \text { Ethnic Minority } & -0.04 & 0.01 & -0.05 & \text { to } & -0.03 & -0.01 & <.0001 \\ \text { Material Deprivation } & -0.13 & 0.01 & -0.14 & \text { to } & -0.12 & -0.03 & <.0001\end{array}$

\section{Predictors}

\begin{tabular}{llllllll} 
Traditional Bullying & -0.51 & 0.01 & -0.51 & to & -0.50 & -0.32 & $<\cdot 0001$ \\
Cyberbullying & -0.23 & 0.01 & -0.25 & to & $-0 \cdot 20$ & -0.03 & $<.0001$ \\
\hline
\end{tabular}

Notes. Coefficients reflect values adjusted and weighted by representativeness of participants across the United Kingdom. B, unstandardized regression slope coefficients. Note bullying behaviours reflect number of traditional or cyberbullying experiences in the past two months. 
Figure 1. Flow chart of What About Youth study participants.

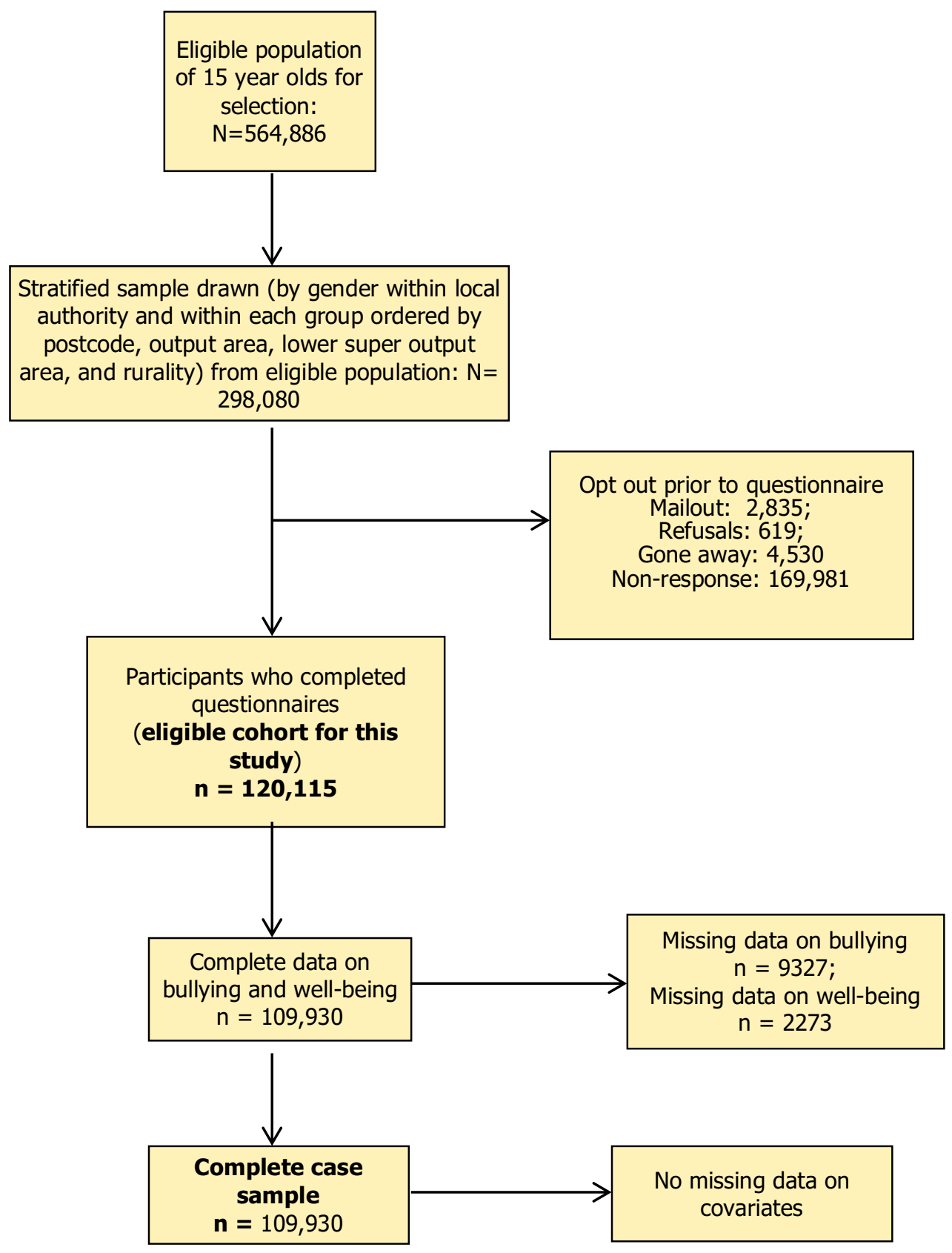


Figure 2. Observed well-being levels across different experiences of bullying.

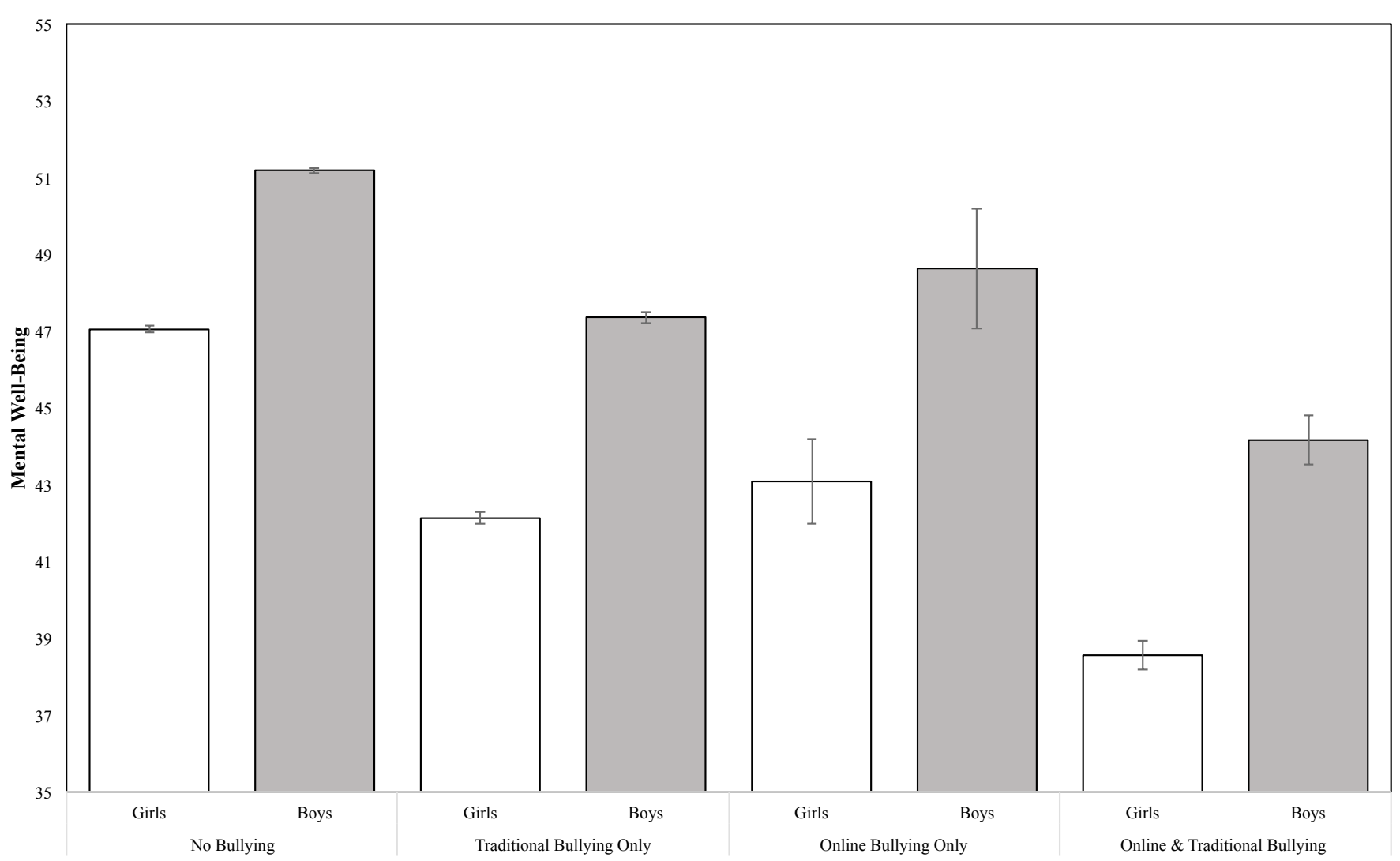

Notes. Point estimates are adjusted and weighted by representativeness of participants across England.All bullying comparisons were statistically significant. All male to female comparisons were statistically significant at the $p<0.001$ level. Error bars denote the 95\% confidence interval for the observed means. 